\title{
The Impact of Mental Toughness Training on Speed and Accuracy of Some Offensive Skills of Field Hockey Junior Players
}

\author{
Hany Mahmoud Abou-bakr ${ }^{1}$, Medhat El-sayed Mostafa ${ }^{2}$ \\ ${ }^{1}$ Physical Education Foundations Department, Faculty of Physical Education for Men, Alexandria University, Egypt \\ ${ }^{2}$ Sport Games Training Department, Faculty of Physical Education for Men, Alexandria University, Egypt
}

\begin{abstract}
This research was conducted to identify the impact of mental toughness training on speed and accuracy of some offensive skills of junior field hockey. Study participants consisted of (32) juniors representing field hockey junior players' aged between (16-18) years old and they were selected from sport club (Albank-Alahly club) at Alexandria, Egypt. Two tools were used which are Mental Toughness inventory, and field hockey offensive skills tests in order to collect the necessary data. The mental toughness exercises had a significant positive effect on the speed and accuracy of some offensive skills of junior field hockey through improvement of mental toughness abilities.
\end{abstract}

Keywords: Mental toughness training - offensive skills - field hockey

\section{Introduction}

$\mathrm{F}$ ield hockey is one of the most popular team sports in the world; it is the second largest team sport by participants after soccer. (Murtaugh, 2001) Field hockey is a multiple high intensity activity sport with a multidirectional nature, to obtain expert status in field hockey; players must excel in no less than four domains: physiological, technical, tactical, and psychological. (Anbarasu, 2013)

(Sugarman, 1998) stated that athletes spend so much time on physical practice to get an edge in the competition, yet they ignore one of the basic aspects of the game that is mental skill. Coaches and athletes are becoming aware of the fact that in today's world, competition is tough, even though athletes are physically fit, yet the margin for victory is slim. Therefore, coaches and players are realizing that to get ahead they need an added resource, and that is a trained mind. A competitive sport is $85-90 \%$ a mental game, but unfortunately, many times physical aspect of the game is magnified at the expense of the other. Combining the two elements mental training and technical training, gives the players an opportunity to establish a consistent, peak performance every time they step on the field. (Bhambri, et al., 2005)

To perform at top level, players have to perform under high pressure. It is therefore not surprising that psychological characteristics such as motivation, confidence, anxiety control, mental preparation, team emphasis, and concentration which are commonly conceptualized under the umbrella term mental toughness often distinguish elite from non-elite performers. Mental toughness can not only play a decisive role in an important match; they are also needed to develop a successful sports career. (Gucciardi, et al., 2012).

Mental Toughness (MT) refers to an inner focus and commitment to rise above challenges when facing adversity (Madrigal, et al., 2013). Many coaches view MT as a quality that must be considered in the recruitment of athletes. Coaches' reason that those who possess a high degree of MT perform better because they are more focused on the task at hand, rather than obsessing about failure and defeat (Weinberg, Butt, \& Culp, 2011). Mentally tough performers are disciplined thinkers who respond to pressure in ways which enable them to remain feeling relaxed, calm and energized because they have the ability to increase their flow of positive energy in crisis and adversity. They also have the right attitudes regarding problems, pressure, mistakes and competition. (Golby , \& Sheard, 2004)

Researchers have acknowledged that MT is important for, and often attributed as the cause of, successful performance (Bull et al., 2005; Gould et al., 2002; Gould, Eklund, \& Jackson, 1993; Krane \& Williams, 2006 ;). (Loehr, 1995) suggested that athletes' MT was responsible for $50 \%$ of success in competition. (Jones et al. 2002) suggested that, "Mental toughness is probably one of the 
most used but least understood terms used in applied sport psychology"

Field hockey Sport is a physical and mental challenge. In field hockey lots of movements and skills are involved so a high level of physical and mental demand is required for match play. The game of field hockey involves walking, jogging, sprinting in varied directions with and without ball. A high number of accelerations and decelerations, associated with the large number of changes in direction of play create an additional load to the body and mind involved as in field hockey (Manna, et al, 2010).The ability to maintain high levels of concentration remain relaxed with the confidence to succeed is a skill essential to top level performance in field hockey. This skill also has the potential to transcend sport and affect players' everyday lives. (Tibbert, 2013)

To develop the mental toughness for success at high levels, training programs starting at our junior hockey teams are required. The training programs should include key mental components identified by sport psychologists: concentration, confidence, motivation, and handling pressure. As a player progresses through the training program, the mental training aspect will evolve from: having fun and respecting opponents; to visualization and self-awareness; to goal setting, relaxation, and positive self-talk. (Tibbert, 2013)

After a thorough review of available previous studies, the two researchers not found studies that handling the mental toughness training on junior field hockey players, this Prompting the two researchers to conduct this study that aimed to identifying the impact of mental toughness training on speed and accuracy of some offensive skills of junior field hockey.

\section{Research Aim}

This study aimed to; identify the impact of mental toughness training on speed and accuracy of some offensive skills of junior field hockey.

\section{Material and Methods}

\section{Research design:}

This research followed the experimental research design method as it suits the nature of this research.

\section{Setting:}

The two researchers selected the study subjects from the sport club (Albank-Alahly club) at Alexandria, Egypt.

Subjects:
Total sample was (32) juniors aged between (16-18 years), attended the previous club in the period of 14th March to 29 th June 2016. The pilot study was conducted on (10) players while the remaining (22) players divided randomly into two equal groups (experimental group $=11$ player, and control group $=11$ player .

\section{Study tools:}

\section{Tool I: Mental Toughness inventory (MTI)} (Mukhaimar, 2002) (Appendix I):

This tool was designed by Mukhaimar, 2002. This tool was used by the two researchers in order to assess the required data. This tool is consisted of 23 questions under three dimensions which are commitment, challenge, and control.

Tool II: field hockey offensive skills tests (Abd-Allah, 2006) (Appendix II):

Ball push accuracy

Ball push velocity

Ball flick velocity

Ball flick accuracy

Ball scoop accuracy

Ball scoop velocity

Ball hit velocity with flat side

Ball hit accuracy with flat side

\section{Procedures:}

- Experimental design was used that classified participants into two groups, experimental group who used mental toughness training and other control group who used traditional training related to field hockey.

- For testing the validity of mental toughness inventory, the two researchers used internal consistency method and its result indicated that it has high stability interaction. The reliability was tested by using test re test method, and the alpha Kronbak coefficient. (Appendix III)

- For testing the validity of field hockey offensive skills, the two researchers used concurrent validity method and its result indicated that this tool discriminate between the special and non-special group. The reliability was tested by using test re test method. (Appendix III)

- The mental toughness training sessions was developed in accordance with the scientific principles (Appendix IV)

The main training session aspects: 
The mental toughness training included, a (muscle and respiratory relaxation, visualize relaxing, self-confidence, focus attention, sports motivation achievement, always thinking as a winner, modified self-talking, performance steadily under pressure, , build team unity, and quick return to a normal state after the failure).

- Pre measurements were conducted for control and experimental groups in mental toughness and offensive skills.

- The two researchers implemented the proposed training on the experimental research sample. Training implementation time has been determined by (8) weeks. Training session's frequency has been determined by (3) training sessions/week.

- Post measurements were conducted for control and experimental groups in mental toughness and offensive skills, with the same pre-measurement instructions, terms and conditions. Measurement results data were dumped in specially prepared in sheets for statistically processed.

\section{Statistical analysis:}

The IBM SPSS Statistics v21 was used for the statistical analysis of the data. T-test was used to check data normality, and results showed that all parameters had a normal distribution. (Kurtosis, change ratio, Standard deviation, Mean, and T-test) were used in statistical analysis of the data. Researcher adopted 0.05 significance level while analyzing data.

\section{Results}

Table (1)

Statistical Significant Differences between Pre and Post mental toughness measurements for Experimental Group $(\mathrm{n}=11)$

\begin{tabular}{|c|c|c|c|c|c|c|c|}
\hline \multirow{2}{*}{ Variables } & \multicolumn{2}{|c|}{ Pre test } & \multicolumn{2}{c|}{ post test } & \multicolumn{2}{c|}{ mean } \\
\cline { 2 - 7 } difference & Mean & $\begin{array}{c}\text { Standard } \\
\text { deviation }\end{array}$ & Mean & $\begin{array}{c}\text { Standard } \\
\text { deviation }\end{array}$ & Sig. \\
\hline $\begin{array}{c}\text { First dimension : } \\
\text { (commitment) }\end{array}$ & 31.91 & 2.02 & 42.91 & 3.33 & $* 12.74$ & 0.00 & 34.47 \\
\hline $\begin{array}{c}\text { second dimension : } \\
\text { (control) }\end{array}$ & 29.45 & 1.21 & 38.45 & 2.38 & $* 9.84$ & 0.00 & 30.56 \\
\hline $\begin{array}{c}\text { third dimension : } \\
\text { (challenge) }\end{array}$ & 30.91 & 2.07 & 39.09 & 1.97 & $* 7.91$ & 0.00 & 26.47 \\
\hline Total & 92.27 & 3.50 & 120.45 & 7.03 & $* 11.16$ & 0.00 & 30.54 \\
\hline
\end{tabular}

* Significance at $0.05=2.09$

Table (1) results reveal existence of statistically significant differences between mental toughness pre and postmeasurements for experimental group in favor of post

measurement, calculated $t$ value was ranged between (7.91 and 12.74) and these values are greater than the $t$ significant value at level (0.05).

Table (2)

Statistical Significant Differences between Pre and Post mental toughness measurements for control Group $(n=11)$

\begin{tabular}{|c|c|c|c|c|c|c|c|}
\hline \multirow{2}{*}{ Variables } & \multicolumn{2}{|c|}{ Pre test } & \multicolumn{2}{|c|}{ post test } & \multicolumn{2}{c|}{ mean } \\
\cline { 2 - 7 } & Mean & $\begin{array}{c}\text { Standard } \\
\text { deviation }\end{array}$ & Mean & $\begin{array}{c}\text { Standard } \\
\text { deviation }\end{array}$ & $\mathrm{t}$ & Sig. \\
\hline $\begin{array}{c}\text { First dimension : } \\
\text { (commitment) }\end{array}$ & 31.64 & 1.43 & 37.36 & 5.82 & $* 3.20$ & 0.01 & 18.10 \\
\hline second dimension : (control) & 28.64 & 1.21 & 34.36 & 4.63 & $* 4.47$ & 0.00 & 20.00 \\
\hline third dimension : (challenge) & 29.09 & 2.95 & 36.00 & 4.02 & $* 7.44$ & 0.00 & 23.75 \\
\hline Total & 89.36 & 3.72 & 107.73 & 14.22 & $* 5.01$ & 0.00 & 20.55 \\
\hline
\end{tabular}

\footnotetext{
* Significance at $0.05=2.09$
} 
Table (2) results reveal existence of statistically significant differences between mental toughness pre and postmeasurements for control group in favor of post measurement, calculated t value was ranged between (3.20 and 7.44) and these values are greater than the t significant value at level (0.05).

Table (3)

Statistical Significant Differences for mental toughness post measurements between experimental and control group.

\begin{tabular}{|c|c|c|c|c|c|c|c|}
\hline \multirow{2}{*}{ Variables } & \multicolumn{2}{|c|}{ Experimental group $\mathrm{N}=11$} & \multicolumn{2}{|c|}{$\begin{array}{l}\text { Control group } \\
\qquad \mathrm{N}=11\end{array}$} & \multirow{2}{*}{$\begin{array}{c}\text { mean } \\
\text { difference }\end{array}$} & \multirow{2}{*}{$\mathrm{t}$} & \multirow{2}{*}{ Sig. } \\
\hline & Mean & $\begin{array}{l}\text { Standard } \\
\text { deviation }\end{array}$ & Mean & $\begin{array}{l}\text { Standard } \\
\text { deviation }\end{array}$ & & & \\
\hline $\begin{array}{l}\text { First dimension : } \\
\text { (commitment) }\end{array}$ & 3.33 & 37.36 & 5.82 & 5.55 & $* 2.74$ & 0.01 & 14.84 \\
\hline second dimension : (control) & 2.38 & 34.36 & 4.63 & 4.09 & $* 2.61$ & 0.02 & 11.90 \\
\hline third dimension : (challenge) & 1.97 & 36.00 & 4.02 & 3.09 & $* 2.29$ & 0.03 & 8.59 \\
\hline Total & 7.03 & 107.73 & 14.22 & 12.73 & $* 2.66$ & 0.02 & 11.81 \\
\hline
\end{tabular}

* Significance at $0.05=2.09$

Table (3) finding reveals that, existence of statistically significant differences at the level (0.05) in all dimensions of mental toughness in favor of the experimental group, calculated $t$ value ranged between (2.29 to 2.74) and these values are greater than the $\mathrm{t}$ significant value at level (0.05).

Table (4)

Statistical Significant Differences between Pre and Post offensive skills measurements for Experimental Group $(\mathrm{n}=11)$

\begin{tabular}{|c|c|c|c|c|c|c|c|}
\hline \multirow[b]{2}{*}{ Variables } & \multicolumn{2}{|c|}{ Pre test } & \multicolumn{2}{|c|}{ post test } & \multirow[b]{2}{*}{$\begin{array}{c}\text { mean } \\
\text { difference }\end{array}$} & \multirow[b]{2}{*}{$\mathrm{t}$} & \multirow[b]{2}{*}{ Sig. } \\
\hline & Mean & $\begin{array}{l}\text { Standard } \\
\text { deviation }\end{array}$ & Mean & $\begin{array}{l}\text { Standard } \\
\text { deviation }\end{array}$ & & & \\
\hline Ball push accuracy & 0.91 & 1.22 & 2.64 & 0.92 & $* 5.19$ & 0.00 & 190.00 \\
\hline Ball push velocity & 9.79 & 1.58 & 8.18 & 1.08 & $* 8.21$ & 0.00 & 16.43 \\
\hline Ball flick accuracy & 2.09 & 1.38 & 3.36 & 1.03 & $* 6.53$ & 0.00 & 60.87 \\
\hline Ball flick velocity & 3.55 & 0.69 & 4.55 & 0.52 & $* 7.42$ & 0.00 & 28.21 \\
\hline Ball scoop accuracy & 5.00 & 1.48 & 6.36 & 1.03 & $* 3.52$ & 0.01 & 27.27 \\
\hline Ball scoop velocity & 8.60 & 1.87 & 6.64 & 1.36 & $* 5.41$ & 0.00 & 22.85 \\
\hline Ball hit accuracy with flat side & 4.09 & 0.94 & 5.55 & 0.69 & $* 9.24$ & 0.00 & 35.56 \\
\hline Ball hit velocity with flat side & 8.74 & 1.35 & 7.55 & 0.93 & $* 4.38$ & 0.00 & 13.70 \\
\hline
\end{tabular}

* Significance at $0.05=2.09$

Table (4) results reveal existence of statistically significant differences between offensive skills pre and post- measurements for experimental group in favor of post measurement, calculated $\mathrm{t}$ value was ranged between (3.52 and 9.24) and these values are greater than the $t$ significant value at level (0.05). 
Table (5)

Statistical Significant Differences between Pre and Post offensive skills measurements for Control Group $(\mathrm{n}=11)$

\begin{tabular}{|c|c|c|c|c|c|c|c|}
\hline \multirow{2}{*}{ Variables } & \multicolumn{2}{|c|}{ Pre test } & \multicolumn{2}{|c|}{ post test } & \multirow{2}{*}{$\begin{array}{c}\text { mean } \\
\text { difference }\end{array}$} & \multirow[b]{2}{*}{$\mathrm{t}$} & \multirow{2}{*}{ Sig. } \\
\hline & Mean & $\begin{array}{l}\text { Standard } \\
\text { deviation }\end{array}$ & Mean & $\begin{array}{l}\text { Standard } \\
\text { deviation }\end{array}$ & & & \\
\hline Ball push accuracy & 1.09 & 1.14 & 1.73 & 0.90 & $* 2.61$ & 0.03 & 58.33 \\
\hline Ball push velocity & 9.65 & 1.53 & 9.00 & 2.37 & 1.42 & 0.19 & 6.78 \\
\hline Ball flick accuracy & 1.91 & 1.30 & 2.27 & 0.90 & 1.79 & 0.10 & 19.05 \\
\hline Ball flick velocity & 3.64 & 1.03 & 3.45 & 1.04 & 0.69 & 0.51 & 5.00 \\
\hline Ball scoop accuracy & 4.73 & 1.10 & 4.64 & 1.03 & 0.27 & 0.80 & 1.92 \\
\hline Ball scoop velocity & 8.61 & 1.58 & 8.07 & 1.21 & 1.86 & 0.09 & 6.23 \\
\hline $\begin{array}{l}\text { Ball hit accuracy with flat } \\
\text { side }\end{array}$ & 3.91 & 0.83 & 4.45 & 1.13 & $* 2.63$ & 0.03 & 13.95 \\
\hline $\begin{array}{l}\text { Ball hit velocity with flat } \\
\text { side }\end{array}$ & 8.82 & 1.16 & 8.60 & 0.93 & 0.57 & 0.58 & 2.52 \\
\hline
\end{tabular}

Table (5) findings reveal existence of statistical significant differences in some offensive skills between pre and postmeasurements for control group namely (Ball push accuracy, and Ball hit accuracy with flat side) in favor of post measurement. Calculated $t$ value was ranged between
(2.61 and 2.63) and these values are greater than the $t$ significant value at level (0.05). While, the remaining offensive skills differences were found that not statistically significant.

Table (6)

Statistical Significant Differences for offensive skills post measurements between experimental and control group

\begin{tabular}{|c|c|c|c|c|c|c|c|c|}
\hline \multirow{2}{*}{ Variables } & \multicolumn{2}{|c|}{$\begin{array}{c}\text { Experimental group } \mathrm{n} \\
=11\end{array}$} & \multicolumn{2}{|c|}{$\begin{array}{l}\text { Control group } \\
\qquad \mathrm{n}=11\end{array}$} & \multirow{2}{*}{$\begin{array}{c}\text { mean } \\
\text { difference }\end{array}$} & \multirow{2}{*}{$\begin{array}{c}\mathrm{T} \\
\text { value }\end{array}$} & \multirow{2}{*}{$\operatorname{sig}$} & \multirow{2}{*}{$\begin{array}{l}\text { Change } \\
\text { ratio }\end{array}$} \\
\hline & Mean & Std. Deviation & Mean & $\begin{array}{c}\text { Std. } \\
\text { Deviation }\end{array}$ & & & & \\
\hline Ball push accuracy & 2.64 & 0.92 & 1.73 & 0.90 & 0.91 & $* 2.33$ & 0.03 & 52.63 \\
\hline Ball push velocity & 8.18 & 1.08 & 9.00 & 2.37 & 0.82 & 1.04 & 0.31 & 9.09 \\
\hline Ball flick accuracy & 3.36 & 1.03 & 2.27 & 0.90 & 1.09 & $* 2.64$ & 0.02 & 48.00 \\
\hline Ball flick velocity & 4.55 & 0.52 & 3.45 & 1.04 & 1.09 & $* 3.12$ & 0.01 & 31.58 \\
\hline Ball scoop accuracy & 6.36 & 1.03 & 4.64 & 1.03 & 1.73 & $* 3.94$ & 0.00 & 37.25 \\
\hline Ball scoop velocity & 6.64 & 1.36 & 8.07 & 1.21 & 1.44 & $* 2.62$ & 0.02 & 17.79 \\
\hline $\begin{array}{l}\text { Ball hit accuracy with flat } \\
\text { side }\end{array}$ & 5.55 & 0.69 & 4.45 & 1.13 & 1.09 & $* 2.74$ & 0.01 & 24.49 \\
\hline $\begin{array}{l}\text { Ball hit velocity with flat } \\
\text { side }\end{array}$ & 7.55 & 0.93 & 8.60 & 0.93 & 1.05 & $* 2.65$ & 0.02 & 12.26 \\
\hline
\end{tabular}

* Significance at $0.05=2.09$

Table (6) This table reveals that, existence of statistically significant differences at the level (0.05) in offensive skills tests in favor of experimental group, calculated $\mathrm{t}$ value ranged between (2.33 to 3.94) and these values are greater than the $t$ significant value at level (0.05), while there are no statistically significant differences in (Ball push velocity) test.

\section{Discussion}

As regard experimental group, table (1) revealed statistical significant differences between pre and post mental toughness measurements with high improvement in post measurements. The change ratio between both measurements was ranged between $(26.47 \%$ and $34.47 \%)$. 
This improvement in mental toughness measurements within experimental group can be attributed to the effectiveness of the mental toughness training that used by experimental group. This finding is consistent with (Ray, 2003) which revealed that mental toughness was acquired trait that can be learned.

Table (2) results clarified that existence of statistical significant differences between pre and postmeasurements in mental toughness for control group in favor of post measurement. The change ratio between both measurements in the same group was ranged between (18.10\% and $23.75 \%$ ). Although presence of improvement in control group but it still less than the improvement that occurred in experimental group.

Table (3) revealed that statistical significant differences for post-measurements mental toughness measurements' between experimental and control group in favor of experimental group. Also the change ratios ranged between $(8.59 \%$ and $14.84 \%)$ in all mental toughness dimensions in favor of the experimental group. This improvement in mental toughness within experimental group can be attributed to the effectiveness of the mental toughness exercises that used by experimental group. While the control group trained with traditional exercises.

In this regard evidence from two qualitative studies using elite athletes (Bull et al., 2005; Connaughton et al., 2008) implicates the crucial role of environmental influences such as motivational climate, parental influence, upbringing, and exposure to tough environments (competitive) in the development of mental toughness. Also (Clough et al., 2002) conceptualized mental toughness as a personality trait that can be developed. Furthermore, the role of mental skills training in the development of mental toughness has received some support through the work of (Sheard \& Golby., 2006), those researchers found that a 7-week mental skills training program led to significant increases in both the performance and self-rated mental toughness of high performing adolescent swimmers.

Regarding offensive skills as clarified in Table (4). It was observed that statistical significant differences between pre and post measurements for experimental group in favor of post measurement. The change ratio between both measurements in the same group was ranged between $(13.70 \%$ and $190.00 \%)$. This improvement in offensive skills could be attributed to mental toughness exercises which leads to higher achievement level in offensive skills. In this regard (Loher.,1993) revealed that Psychological skills that reflect the mental toughness contribute to not less than $50 \%$ in athletic achievement.
These results came in agreement with (Jones et al., 2002) claimed that mentally tough athletes were 'better' at psychologically coping with demanding circumstances.

Concerning control group, Table (5) results revealed that statistical significant differences between pre and post measurements in some offensive skills namely (Ball push accuracy, and Ball hit accuracy with flat side) in favor of post measurement. The change ratio between both measurements in the same group was ranged between $(1.92 \%$ and $58.33 \%)$. These findings attributed this improvement that has been occurred to the traditional program, which they trained with and players commitment of presence in the training where repeating of performance can lead to improvement.

Table (6) showed that high improvement in experimental group than control group in offensive skills, Change ratio was ranged between $(9.09 \%$ and $52.63 \%)$. this improvement could be reasonable to the mental toughness exercises which in turn lead to performance improvement. In the same line (Golby, \& Sheard, 2004) demonstrated that performers playing at the highest standard (International players) scored significantly higher in mental toughness subscales than others.

In a study of the psychological characteristics of Olympic champions, (Gould, et al..,2002) identified mental toughness as the mental skill factor most frequently cited as a significant contributor to sports performance enhancement. Mental toughness, there remains a dearth of evidence demonstrating links between their characteristics and sporting achievement, (Golby, et al., 2003).

The current research findings are consistent with (Douglas Wayne, 2010) where he found that, mental toughness is the most important factor in achieving athletic achievement, and emphasizes the need to the attention of sports trainers to develop the mental toughness of their players. Therefore, mental toughness training had a significant effect in improving the speed and accuracy of some offensive skills of junior field hockey.

\section{Conclusion}

The mental toughness training had a significant positive effect on the speed and accuracy of some offensive skills of junior field hockey through improvement of mental toughness abilities. Therefore, the two researchers recommended that, mental toughness training to be an essential part in field hockey training.

\section{References}


1- Abdullah, M. (2006): Comprehensive setting in hockey, Ayat center for printing and publishing, Zagazig.

2- Anbarasu, P. (2013). Construction of Skill Tests and Compilation of Norms for Selected Field Hockey Skills. Indian Journal of Research.2 (12), 221-223.

3- Bhambri, E. Dhillon, P.K. Sahni S.P. (2005). Effect of Psychological Interventions in Enhancing Mental Toughness Dimensions of Sports Persons. Journal of the Indian Academy of Applied Psychology. 31(2), 65-70.

4- Bull, S. J., Shambrook, C. J., James, W., \& Brooks, J. E. (2005). Towards an understanding of mental toughness in elite English cricketers. Journal of Applied Sport Psychology, 17, 209-227.

5- Bull, S., Shambrook, C., James, W., \& Brooks, J. (2005). Towards an understanding of mental toughness in elite English cricketers. Journal of Applied Sport Psychology, 17, 209-227.

6- Clough, P. J., Earle, K., \& Sewell, D. (2002) mental toughness: the concept and its measurement. In I. Cockerill (Ed.), Solutions in Sport Psychology (pp. 3243). London: Thomson .

7- Connaughton, D., Wadey, R., Hanton, S., \& Jones, G. (2008). The development and maintenance of mental toughness: Perceptions of elite performers. Journal of Sport Sciences, 26(1), 83-95 .

8- Douglas Wayne Minnix. (2010). Mental Toughness in The Classical Martial Arts, Dissertation Submitted to The Faculty of The Virginia Polytechnic Institute and State University, USA .

9- Golby J , Sheard M(2004). Mental toughness and hardiness at different levels of rugby league. Personality and Individual Differences. 37, 933-942

10- Golby, J., Sheard, M., \& Lavallee, D. (2003). A cognitive-behavioral analysis of mental toughness in national rugby league football teams. Perceptual and Motor Skills, 96, 455-462.

11- Gould, D., Dieffenbach, K., \& Moffett, A (2002). Psychological Characteristics and Their Development in Olympic Champions. Journal OF Applied Sport Psychology, 14, pp 172- 204,

12- Gould, D., Eklund, R. C., \& Jackson, S. A. (1993). Coping strategies used by U.S. Olympic wrestlers. Research Quarterly for Exercise and Sport, 64, 78-93.

13- Gucciardi D, Hanton S, Mallett C (2012) .Progressing Measurement in Mental Toughness: A Case Example of the Mental Toughness Questionnaire: 48. Sport, Exercise, and Performance Psychology. 1, (3), 194-214

14- James Loehr. (1993). The New Toughness Training For Sports. New York, New York, Penguin Book, USA.,

15- Jolly Ray. (2003). Mental Toughness, Level III Hockey Coaching Course, Karnataka State Hockey Association, Bangalore.

16- Jones, G., Hanton, S., \& Connaughton, D. (2002). What is this thing called mental Toughness? An investigation of elite sport performers. Journal of Applied Sport Psychology, 14, 205-218.

17- Krane, V., \& Williams, J. M. (2006). Psychological characteristics of peak performance. In J. M. Williams (Ed.), Applied sport psychology: Personal growth to peak performance (5th ed., pp. 207-227). Boston, MA: McGraw-Hill.

18- Loehr, J. (1995). The new toughness training for sports. New York, NY: Dutton.

19- Madrigal L, Hamill S, Gill D.(2013). Mind over Matter: The Development of The Mental Toughness Scale (MTS). The Sport Psychologist, 27, 62-77.

20- Manna I,, Khanna G , Dhara P.(2010). Effect of Training on Anthropometric, Physiological and Biochemical Variables of Elite Field Hockey Players. International Journal of Sports Science and Engineering. 4 (4), 229-238.

21- Mukhaimar, E. (2002). Mental toughness inventory, the Anglo-Egyptian Library, Cairo.

22- Murtaugh, K. (2001). Injury patterns among female field hockey players. Official Journal of the American College of Sports Medicine), 33(2):201-207.

23- Sheard, M., \& Golby, J. (2006). Effect of psychological skills training program on swimming performance and positive psychological development. International Journal of Sport and Exercise Psychology, 2, $7-24$.

24- Stephanie Jane Tibbert (2013). Mental Toughness and Overtraining Behaviors. College of sport and exercise science Victoria University.

25- Sugarman, K (1998). Why mental training Available at www.psychwww.com/sports/mt.htm

26- Weinberg, R., Butt, J., \& Culp, B. (2011). Coaches' views of mental toughness and how it is built. International Journal of Sport and Exercise Psychology, 9, 156-172. 